\title{
Soil Stabilization For Pavements Using Geofabrics Based On California Bearing Ratio
}

\author{
R.Madeswaran, R.Sai Kumar, Md.Saleem, Ch.Maheshwar Reddy
}

\begin{abstract}
India has the largest road network however the prevailing roads ar structurally inadequate to accommodate the current volume of traffic. Use of geosynthetics is compatible and conjointly effective within the method of up soil properties. the current study conducts experiment on the performance of geotextile (woven and non-woven) as soft subgrade and unbound gravel in unpaved versatile pavement system victimization $C A$ Bearing magnitude relation (CBR) take a look at. Reinforcement magnitude relation comparison of woven and non-woven geotextile reinforcenment supported CMB load penetration take a look at indicates that the performance is improved with the inclusion of geotextile.
\end{abstract}

Keywords: versatile pavement, Geo textile, CBR test,

\section{INTRODUCTION}

Soil could be a non-homogeneous material whose engineering behavior depends on wetness content, density. Changes in volume and strength will cause roughness and pavement structures starts deteriorating within the style of cracking and reduces the riding quality. The foremost objective of stabilization throughout the development of roads is to boost its engineering performance and to scale back the development price by use of domestically offered materials.

The subgrade with adequate bearing capability or CMB price will carry the expected traffic by providing a granular material fittingly. At locations wherever soil CMB price is a smaller amount than a pair of, pavement encounters the rutting and shear failure issues. varied ground improvement techniques like excavation and replacement of unsuitable material, chemical stabilization ar ordinarily adopted in sites however the price of those processes ar high and can't be adopted all told places. This downside will be solved to tiny extent by victimization geotextile that embody natural geo synthetics like fiber, jute, sisal and artificial chemical compound materials like Polyester, nylon, plastic, synthetic resin, A geotextile is factory-made the same as material interweaving.

Revised Manuscript Received on April 19, 2019.

R.Madeswaran, Professor, Department of Civil Engineering, Siddhartha Institute of Technology and Sciences, Hyderabad, Telangana, India.

Mr.R.Sai Kumar, Assistant Professor, Department of Civil Engineering, Siddhartha Institute of Technology and Sciences, Hyderabad, Telangana, India.

Md.Saleem, Assistant Professor, Department of Civil Engineering, Siddhartha Institute of Technology and Sciences, Hyderabad, Telangana, India.

Ch.Maheshwar Reddy Assistant Professor, Department of Civil Engineering, Siddhartha Institute of Technology and Sciences, Hyderabad, Telangana, India. Reinforcement magnitude relation.

In this perspective, fibre is additional appropriate for rural building over soft clay because it is that the price effective alternate to ancient methodology. Bharat is that the 1 st largest country to supply fiber fiber from the husk of coconut. Recently, fiber fiber were spun into yarn and woven to get woven nettings.

Geo textile reinforcement serves the essential perform of separating base layer from subgrade soil and reinforces the composite system thereby up their overall strength and repair life. in contrast to the artificial merchandise, geotextiles ar perishable and doesn't create any environmental issues.

\section{OBJECTIVES OF PROJECT}

To calculate the CMB values of fiber Geotextile strengthened and unreinforced sub grade within the laboratory.

To study the performance of rural road strengthened with fiber geotextile.

\section{NEED FOR THE CURRENT PROJECT}

The fiber geotextile encourage be glorious reinforcement and supply protection for the road network over areas containing soft clays underneath water logged conditions

It also can be applied for soils with low bearing capability and improper drain of that end in early failure of roads.

Coir geotextiles also are set for mound protection and subgrade enhancements were chosen for performance evaluations studies.

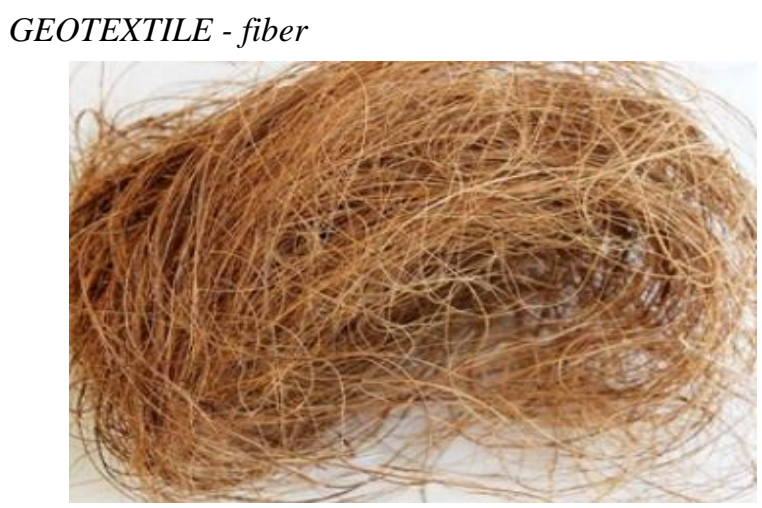

Fig. 1 Coconut coir

fiber is extracted from outer layer of coconut fruit that is absolutely aged. Figure. one shows the coconut fiber extracted that ar used either within the style of woven or non-woven.

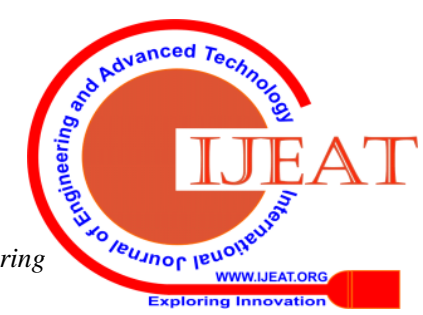




\section{EXPERIMENTAL INVESTIGATION}

\section{MATERIALS USED}

The experimental investigation was distributed for 2 materials i.e., soil and geotextile fiber. For the study, the soil was collected from 3 completely different locations. For laboratory tests, native soil and stuffed soil was collected. the current study concerned non woven geotextiles as shown Figure a pair of.

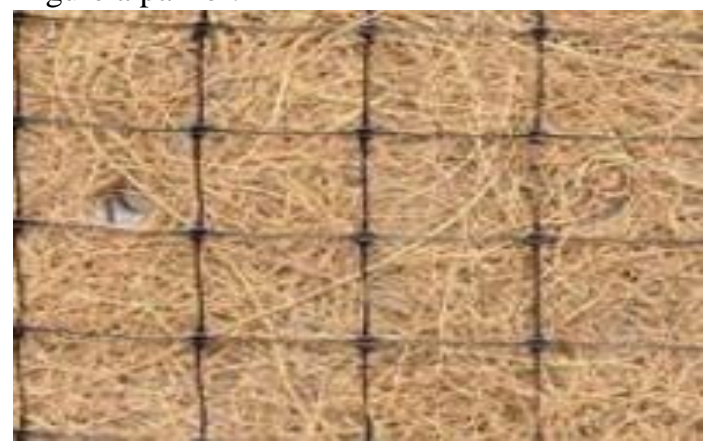

Fig.2 Non-woven geotextiles

The CA Bearing magnitude relation could be a live of resistance of a fabric to penetration of ordinary plunger underneath controlled conditions. CA Division of Highways developed a way for classifying and evaluating soil- sub grade and for style of versatile pavements.

In the gift study, CMB take a look at was conducted to guage the variation in load carrying capability for each strengthened and unreinforced pavements. The geotextile was placed at varied positions within the mould and therefore the take a look at was distributed on plain soil and strengthened soil like a shot once compaction and once four hours of soaking. Geotextile was placed one at prime, another at tierce and one at middle.

\section{RESULTS AND DISCUSSION}

The results ar obtained taking average of 3 trails for every. The results of CMB take a look at were within the style of optimum wetness content and dry density. Indian customary code was followed for conducting CMB take a look at. Penetration stress in $\mathrm{kPa}$ was computed to get $\mathrm{CMB}$ values once the conduct of take a look at. CMB price is calculated victimization the formula

The mobilization of soil strength via reinforcing geosynthetic material is predicated on the final lateral restrains caused by the resistance inter- action and interlocking between soil sample and geosynthetics. The strength mobilization thanks to the inclusion of geosynthetics was terribly distinctive within the soil samples with terribly low CMB.

1. CMB price will increase once strengthened with fiber geo textile.

2. CMB price of strengthened soil is over for strengthened soil underneath soaked condition.

3. there's a rise in CMB price for soil strengthened within the middle.

\section{CONCLUSION}

The soil stabilization via reinforcing fiber geotextile material is predicated on the interlocking and interaction between soil sample and geotextile. The inclusion of fiber geotextile provides stabilization and strength that is extremely distinctive in soil samples.

The following ar the conclusions derived from the current study.

The impact of fiber geotextile was investigated by conducting a series of CMB take a look at.

The CMB price is improved by providing geotextile as reinforcement to the soil that indicates that it improves the soil strength conjointly.

From the current study, it's finished that, fiber geotextile strengthened soil can perform higher by up load carrying capability, higher stress distribution and lesser deformation than unreinforced soil.

It is conjointly derived that, fiber geotextiles offers effective sub grade improvement and soil structure protection.

Hence it's suggested to construct take a look at tracks victimization completely different forms (unwoven and woven) fiber geotextile for various soil conditions to guage their performances.

\section{REFERENCES}

1 Ajitha, B., Jayadeep, T., 1997 "Interfacial frictional properties of geotextiles and biomats" Proceedings of Indian Geotechnical Conference, Vadodara, India, Vol.1, pp.287-290.

2 Shaheem S and Tomy Cyriac 2013 "Performance evaluation of coir geo-textiles as earth reinforcement in soil structures", American Journal of Engineering Research, Volume-1, pp-49-53.

3 M Rudramurthy, M B Vikram, 2016, "Effect of Geotextiles on CBR Values", International Journal of Emerging Trends in Engineering and Development, Issue 6, Vol. 1.

4 Anderson, P., Killeavy, M., 1989. "Geotextiles and geogrids-cost effective alternate materials for pavement design and construction", Geosynthetics, San Diego, USA, vol. 2, 353-364.

5 Babu, K.K., Beena, K.S., Raji, A.K., 2008."Design of Coir Geotextile reinforced Road using IRC method". Highway Research Journal, Special Issue.

6 Cancelli, A., Montanelli, F., 1999. "In-ground test for geosynthetic reinforced flexible paved roads". Proceedings of Geosynthetics, Vol. 2, Boston,USA, pp. 863-879.

7 Chauhan, M.S., Mittal, S., Mohanty, B., 2008. "Performance evaluation of silty sand subgrade reinforced with fly ash and fibre" Geotextiles and Geomembranes, 26 (5),429-435.

8 Datye. K. R, Gore. V. N., (1994) "Application of natural geotextiles and related products" Geotextiles and Geomembrane 13,371-388.

9 Mahdi Taghipour Masoumi, Ali Abdi Kordani, Mahmoud Nazirizad 2017, "Experimental Study of Geotextile Effect on Improving Soil Bearing Capacity in Aggregate Surfaced Roads", International Journal of Civil and Environmental Engineering, Vol 11, No1.

10 Dr. P. Senthil Kumar, R.Rajkumar 2012, Effect of Geotextile on CBR Strength of Unpaved Road with Soft Subgrade, EJGE, Vol. 17. 